Pacific Journal of Mathematics

EXTENSIONS OF INEQUALITIES OF THE LAGUERRE AND
TURÁN TYPE 


\title{
EXTENSIONS OF INEQUALITIES OF THE LAGUERRE AND TURÁN TYPE
}

\author{
MerRell L. Patrick
}

It is shown that

$$
\sum_{j=0}^{2 k} \frac{(-1)^{j+k}}{(2 k) !}\left(\begin{array}{c}
2 k \\
j
\end{array}\right) F^{(n+j)}(z) F^{(n+2 k-j)}(z) \geqq 0,
$$

for $-\infty<z<\infty, n \geqq 1$ and $k \geqq 0$, where $F(z)$ is an entire function of a special type. For $k=1$ this simply is the well known Laguerre inequality

$$
\left(F^{(n+1)}(z)\right)^{2}-F^{(n)}(z) F^{(n+2)}(z) \geqq 0
$$

$-\infty<z<\infty, n \geqq 0$. From these inequalities we obtain the inequalities

$$
\sum_{j=0}^{2 k} \frac{(-1)^{j+k}}{(2 k) !}\left(\begin{array}{c}
2 k \\
j
\end{array}\right) u_{n+j}(x) u_{n+2 k-j}(x) \geqq 0
$$

which hold for such values of $x$, for which the functions $u_{n}=u_{n}(x)$ have a generating function of the type

$$
\sum_{n=0}^{\infty} u_{n} \frac{z^{n}}{n !}=F(z)
$$

1. Introduction. Consider the entire function of the form

$$
F(z)=C e^{-\alpha z^{2}+\beta z} z^{r} \prod_{m}\left(1-z / z_{m}\right) e^{z / z_{m}}
$$

where $\alpha \geqq 0, C, \beta$ and all $z_{m}$ are real, and $\sum_{m} z_{m}^{-2}$ is convergent. These functions have been studied by Laguerre (see Borel [1; pp. 32-47]), Pólya and Schur [9], and others. Apart from constant factors, these functions are the only ones which are limits of polynomials with real $]$ zeros only.

In $\S 2$ we show, for integers $n \geqq 0$, that

$$
\left|F^{(n)}(x+i y)\right|^{2}=\sum_{k=0}^{\infty} L_{k}\left(F^{(n)} ; x\right) y^{2 k}
$$

where

$$
L_{k}\left(F^{(n)} ; x\right)=\sum_{j=0}^{2 k} \frac{(-1)^{j+k}}{(2 k) !}\left(\begin{array}{c}
2 k \\
j
\end{array}\right) F^{(n+j)}(x) F^{(n+2 k-j)}(x)
$$

and $F^{(n)}(z)$ denotes the $n$th derivative of $F(z)=F^{(0)}(z)$. Furthermore, we show that

$$
L_{k}\left(F^{(n)} ; x\right) \geqq 0
$$


for each $n \geqq 0, k=0,1,2, \cdots$, and all real $x$. Patrick [8] obtained inequality (1.4) for polynomials with real zeros only. For $k=1,(1.4)$ is the well known and useful Laguerre inequality.

$$
\left(F^{(n+1)}(z)\right)^{2}-F^{(n)}(z) F^{(n+2)}(z) \geqq 0,-\infty<z<\infty, n \geqq 0 .
$$

Finally, in $\S 3$, we use (1.4) to obtain the inequalities

$$
\sum_{j=0}^{2 k} \frac{(-1)^{j+k}}{(2 k) !}\left(\begin{array}{c}
2 k \\
j
\end{array}\right) u_{n+j}(x) u_{n+2 k-j}(x) \geqq 0
$$

which holds for such values of $x$, for which the functions $u_{n}=u_{n}(x)$ have a generating function of the type

$$
\sum_{n=0}^{\infty} u_{n} \frac{z^{n}}{n !}=F(z)
$$

where $F(z)$ is of the form (1.1).

For $k=1,(1.6)$ is the interesting and much studied Turán inequality

$$
\left(u_{n+1}(x)\right)^{2}-u_{n}(x) u_{n+2}(x) \geqq 0, n \geqq 0 .
$$

In 1948 Szegö [13] called attention to (1.8) for Legendre polynomials. Since that time the inequality has been studied for other special functions by Mukherjee and Nanjundiah [6]; Nanjundiah [7]; Szász [11], [12]; Thiruvenkatachar and Nanjundiah [14]; Venkatachaliengar and Rao [15], and others. These authors have shown that the functions which satisfy (1.8) include the Legendre, Tchebychef, ultraspherical, Hermite and Laguerre polynomials and the Bessel and modified Bessel functions. A summary of these results are contained in Skovgaard [10]. Also in [10], Skovgaard uses the Laguerre inequality (1.5) to obtain the Turán inequality for sequences $u_{n}=$ $u_{n}(x), n=0,1,2, \cdots$ satisfying (1.7). He shows that for such sequences the Turán inequality is a special case of the Laguerre inequality. Then he is able to easily prove the inequality (1.8) for most of the above mentioned functions. These results served as motivation for the work which resulted in this paper.

Some other papers containing results related to the Turán type expressions or inequalities are Carlitz [2]; A. E. Danese [3], [4]; Karlin and Szegö [5]; and Webster [16].

2. "Extended" Laguerre inequalities. We now prove the following theorem concerning entire functions of the form (1.1).

THEOREM 1. Let $F(z)=F(x+i y)$ be an entire function of the 
form (1.1) and let $F^{(n)}(z)$ denote the $n$th derivative of $F(z)$. Then for any integer $n \geqq 0$ and any $z=x+i y \neq \infty$

$$
\left|F^{(n)}(x+i y)\right|^{2}=\sum_{k=0}^{\infty} L_{k}\left(F^{(n)} ; x\right) y^{2 k}
$$

where

$$
L_{k}\left(F^{(n)} ; x\right)=\sum_{j=0}^{2 k} \frac{(-1)^{j+k}}{(2 k) !}\left(\begin{array}{c}
2 k \\
j
\end{array}\right) F^{(n+j)}(x) F^{(n+2 k-j)}(x)
$$

Furthermore

$$
L_{k}\left(F^{(n)} ; x\right) \geqq 0 \quad \text { for } k=0,1,2, \cdots
$$

Proof. We first prove (2.1)-(2.2) for $n=0$. Since $F^{(0)}(z)=F(z)$ is an entire function we can write for any $z$

$$
F(z)=F(x+i y)=\sum_{k=0}^{\infty} A_{k}(F ; x) y^{k}
$$

and

$$
F(\bar{z})=F(x-i y)=\sum_{k=0}^{\infty}(-1)^{k} A_{k}(F ; x) y^{k}
$$

where

$$
A_{k}(F ; x)=\frac{i^{k}}{k !} F^{(k)}(x), \quad k=0,1,2, \cdots
$$

Since $C, \alpha, \beta$, and all $z_{m}$ are real, $\overline{F(z)}=F(\bar{z})$ and so from (2.4) and (2.5) we have

$$
|F(x+i y)|^{2}=\sum_{m=0}^{\infty} C_{m}(F ; x) y^{m}
$$

where

$$
\begin{aligned}
C_{m}(F ; x)= & (-1)^{m} A_{0}(F ; x) A_{m}(F ; x)+(-1)^{m-1} A_{1}(F ; x) A_{m-1}(F ; x) \\
& +\ldots+(-1) A_{m-1}(F ; x) A_{1}(F ; x)+A_{m}(F ; x) A_{0}(F ; x)
\end{aligned}
$$

When $m$ is odd, it follows from (2.6) and (2.8) that

$$
\begin{aligned}
& C_{m}(F ; x) \\
& =\sum_{j=0}^{M}\left(\frac{i^{j}}{j !} \cdot \frac{(-1)^{m-j} i^{m-j}}{(m-j) !}+\frac{i^{m-j}}{(m-j) !} \cdot \frac{(-1)^{j} i^{j}}{j !}\right) F^{(j)}(x) F^{(m-j)}(x) \\
& =\sum_{j=0}^{M} \frac{(-1)^{j} i^{m}}{j(m-j) !}\left[(-1)^{m}+1\right] F^{(j)}(x) F^{(m-j)}(x)=0
\end{aligned}
$$


where $M=[(m+1) / 2]$. When $m$ is even, say $m=2 k$, we have from (2.6) and (2.8)

$$
C_{2 k}(F ; x)=\frac{\left(F^{(k)}(x)\right)^{2}}{(k !)^{2}}+\sum_{j=0}^{k-1} 2 \frac{(-1)^{j+k}}{j !(2 k-j) !} F^{(j)}(x) F^{(2 k-j)}(x) .
$$

It follows easily that $L_{k}\left(F^{(n)} ; x\right)$ in $(2.2)$ with $n=0$ is equal to $C_{2 k}(F ; x)$ in (2.10). From (2.7), (2.9), and (2.10) we have the desired result (2.1)-(2.2) for $n=0$.

We now prove (2.1)-(2.2) for $n \geqq 1$. Skovgaard [10] shows that the derivative of a function of the form (1.1) is also of the form (1.1). Therefore, all derivatives $F^{(n)}(z)$ of $F(z)$ are of the form (1.1) and (2.1)-(2.2) for any $n \geqq 1$ follows from the proof of the $n=0$ case by replacing $F(z)$ by $F^{(n)}(z)$.

Next we prove (2.3) for $n=0$. Using (1.1) we have

$$
\left.|F(z)|^{2}=C^{2} e^{-\alpha\left(z^{2}+\bar{z}^{2}\right.}\right)^{+\beta(z+\bar{z})}(z \bar{z})^{r} \prod_{m}\left(1-z / z_{m}\right)\left(1-\bar{z} / z_{m}\right) e^{z+\bar{z} / z_{m}}
$$

or

$$
\begin{aligned}
& |F(x+i y)|^{2} \\
& =C^{2} e^{-2 \alpha x^{2}+2_{\beta} x} e^{2 \alpha y^{2}}\left(x^{2}+y^{2}\right)^{r} \prod_{m}\left[\left(1-x / z_{m}\right)^{2}+y^{2} / z_{m}\right] e^{2 x / z_{m}} .
\end{aligned}
$$

Since $e^{2 x / z_{m}}$ is real and positive for all $x$ we can write

$$
\prod_{m}\left[\left(1-x / z_{m}\right)^{2}+y^{2} / z_{m}^{2}\right] e^{2 x / z_{m}}=\sum_{k=0}^{\infty} C_{k}(x) y^{2 k}
$$

where $C_{k}(x) \geqq 0$ for $k=0,1, \cdots$, and all $x$. Also $\alpha \geqq 0, C^{2}>0, e^{-2 \alpha x^{2}+\beta x}>0$ for all $x,\left(x^{2}+y^{2}\right)^{r}$ is a polynomial in $y^{2}$ with positive coefficients that are functions of $x$, and $e^{2 \alpha y^{2}}$ is an absolutely convergent series in $y^{2}$ with positive coefficients. Combining all of these facts with (2.12) we have for any $z=x+i y \neq \infty$.

$$
|F(x+i y)|^{2}=\sum_{k=0}^{\infty} F_{k}(x) y^{2 k}
$$

where

$$
F_{k}(x) \geqq 0 \quad \text { for } \quad k=0,1,2, \cdots .
$$

But (2.1) and (2.13) are identical so we have $L_{k}(F ; x)=F_{k}(x) \geqq 0$ for $k=0,1,2, \cdots$, and (2.3) is proved for $n=0$.

As in the proof of (2.1)-(2.2), the proof of (2.3) for $n \geqq 1$ follows immediately by replacing $F(z)$ by $F^{(n)}(z)$ in the above considerations.

For the sake of better understanding of the functions $L_{k}\left(F^{(n)} ; x\right)$ we note that 


$$
\begin{aligned}
L_{0}\left(F^{(n)} ; x\right)= & \left(F^{(n)}(x)\right)^{2} \\
L_{1}\left(F^{(n)} ; x\right)= & \left(F^{(n+1)}(x)\right)^{2}-F^{(n)}(x) F^{(n+2)}(x) \\
L_{2}\left(F^{(n)} ; x\right)= & \frac{\left(F^{(n+2}(x)\right)^{2}}{(2 !)^{2}}-\frac{2 F^{(n+1)}(x) F^{(n+3)}(x)}{1 ! 3 !} \\
& +\frac{2 F^{(n)}(x) F^{(n+4)}(x)}{4 !}
\end{aligned}
$$

and, in general,

$$
\begin{aligned}
L_{k}\left(F^{(n)} ; x\right)= & \frac{\left(F^{(n+k)}(x)\right)^{2}}{(k !)^{2}}-\frac{2 F^{(n+k-1)}(x) F^{(n+k+1)}(x)}{(k-1) !(k+1) !} \\
& +\cdots+(-1)^{k} \frac{2 F^{(n)}(x) F^{(n+2 k)}(x)}{(2 k) !} .
\end{aligned}
$$

We further note that (2.15) is the well-known Laguerre expression and that (2.3) with $k=1$ the corresponding Laguerre inequality. For this reason we call (2.3) the "extended" Laguerre inequalities.

In [8] we show, among other things, that $0 \leqq L_{j}\left(F^{(n)} ; x\right) \leqq$ $L_{j}\left(F^{(n)} ; 1\right), j=0,1,2,3$, for $-1 \leqq x \leqq 1$ when $F(z)$ is restricted to the class of ultraspherical polynomials. We conjecture that a similar inequality holds for $j>4$ over the same class of functions.

3. "Extended" Turán inequalities. Using Theorem 1 of $\S 2$ and the results of Skovgaard [10] we can easily prove the following theorem.

THEOREM 2. Let $u_{n}=u_{n}(x), n=0,1,2, \cdots$, be a system of real functions which for certain values of $x$ have a generating function of the type

$$
\sum_{n=0}^{\infty} u_{n} \frac{z^{n}}{n !}=F(z)
$$

where $F(z)$ is of the form (1.1). Then for those values of $x$

$$
\sum_{j=0}^{2 k} \frac{(-1)^{j+k}}{(2 k) !}\left(\begin{array}{c}
2 k \\
j
\end{array}\right) u_{n+j}(x) u_{n+2 k-j}(x) \geqq 0 \quad \text { for } k=0,1,2, \cdots .
$$

Proof. As indicated by Skovgaard [10], we have for those values of $x$ where $u_{n}=u_{n}(x)$ satisfies (3.1) that $u_{n}=F^{(n)}(0)$. That is for such $x$ inequality (3.2) is a special case of "extended" Laguerre inequality (2.3).

We note for $k=1$ that (3.2) is the interesting Turán inequality

$$
u_{n+1}^{2}(x)-u_{n}(x) u_{n+2}(x) \geqq 0 \text {. }
$$


For this reason we call the inequalities (3.2) the "extended" Turán inequalities.

Skovgaard used (2.3) with $k=1$ to obtain (3.2) with $k=1$ for certain classical functions by indicating their generating functions of the type (1.1). These same generating functions, since they are of type (1.1), will, by Theorem 1 , satisfy (2.3) for $k=0,1,2, \cdots$. Therefore, by Theorem 2, the corresponding set of classical functions will satisfy the "extended" Turan inequalities (3.2). The following is a list of these classical functions:

(3.4) Ultraspherical polynomials

$$
P_{n}^{(\lambda)}(x),-1 \leqq x \leqq 1, \lambda \geqq \frac{1}{2},
$$

(3.5) $p$ th derivative of $P_{n}^{(3)}(x)$

$$
D^{p} P_{n}^{(\lambda)}(x), p \leqq n,-1 \leqq x \leqq 1, \lambda \geqq \frac{1}{2}-p,
$$

(3.6) Laguerre polynomials

$$
L_{n}^{(\alpha)}(x),-\infty<x<\infty, \alpha>-1,
$$

(3.7) $p$ th derivative of $L_{n}^{(\alpha)}(x)$

$$
D^{p} L_{n}^{(\alpha)}(x), p \leqq n,-\infty<x<\infty, \alpha \geqq-p,
$$

(3.8) Hermite polynomials

$$
H_{n}(x),-\infty<x<\infty,
$$

(3.9) $p$ th derivative of $H_{n}(x)$

$$
D^{p} H_{n}(x),-\infty<x<\infty,
$$

(3.10) Sine and cosine functions

$$
\left\{\begin{array}{c}
\cos \\
\sin
\end{array}\right\} n x,-\infty<x<\infty,
$$

(3.11) Bessel functions

$$
J_{n}(x),-\infty<x<\infty,
$$

(3.12) Derivative of Bessel function

$$
J_{n}^{\prime}(x),-\infty<x<\infty,
$$

(3.13) Tchebychef function of first kind 


$$
T_{n}(x),-1 \leqq x \leqq 1,
$$

(3.14) Tchebychef function of second kind

$$
U_{n}(x),-1 \leqq x \leqq 1 .
$$

We point out that (3.4) and (3.5) includes Legendre polynomials and their derivatives.

Generating functions for (3.4), (3.6), (3.8), (3.10), (3.11), and (3.12) can be found in Skovgaard [10]. As in Skovgaard's paper we have analogously, since

$$
D^{p} P_{n}^{(\lambda)}(x)=2^{p} \frac{\Gamma(\lambda+p)}{\Gamma(\lambda)} P_{n \rightarrow p}^{(\lambda+p)}(x), p \leqq n,
$$

that (3.5) satisfies (3.2) because (3.4) does. Also

$$
D^{p} L_{n}^{(\alpha)}(x)=(-1)^{p} L_{n-p}^{(\alpha+p)}(x), p \leqq n,
$$

so (3.7) satisfies (3.2) because (3.6) does. Similarly

$$
D^{p} H_{n}(x)=2^{p} \frac{n !}{(n-p) !} H_{n-p}(x)
$$

and (3.9) satisfies (3.2) because (3.8) does. Finally, (3.13) and (3.14) satisfy (3.2) because (3.10) does.

Using an inductive proof we showed that if $F^{(n)}(z)$ is of the form

$$
F^{(n)}(z)=C e^{\beta z}
$$

then

$$
L_{k}\left(F^{(n)} ; z\right)=0
$$

for $k=1,2, \cdots$ Also, (3.16) holds at multiple zeros of order $k+1$ of $F^{(n)}(z)$. Consequently, given the assumptions of Theorem 2, equality in (3.2) holds for values of $x$ for which $F^{(n)}(z)$ is of the form (3.15), or for which $z=0$ is a zero of multiplicity $k+1$ of $F^{(n)}(z)$.

Acknowledgement. The author is grateful to Professor L. Carlitz for his assistance.

\section{REFERENCES}

1. É. Borel, Lecons sur les fonctions entières (Collection de monographies sur la théorie des fonctions), Paris, 1900; 2 ed. 1921.

2. L. Carlitz, Note on Legendre polynomials, Bull. Calc. Math. Soc., 46 (1954), 93-95.

3. A. E. Danese, Explicit evaluations of Turán expressions, Annali Di Matematica Pura ed. Applicata, (4) 38 (1955), 339-348.

4. _ Some identities and inequalities involving ultraspherical polynomials, Duke Math J., 26 (1959), 349-359. 
5. S. Karlin and G. Szegö, On certain determinants whose elements are orthogonal polynomials, J. d'Analyse Mathématique, 8 (1960/61), 1-157.

6. B. N. Mukherjee and T.S. Nanjundiah, On an inequality relating to Laguerre and Hermite polynomials, Math. Student, 19 (1951), 47-48.

7. T. S. Nanjundiah, $A$ note on an inequality of $P$. Turán for Legendre polynomials, Half-Yearly J. Mysore Univ. Sect. B., N. S., 11 (1950), 57-61.

8. M. L. Patrick, Some inequalities concerning Jacobi polynomials, SIAM J. Math. Anal., 2, May (1971).

9. G. Pólya and I. Schur, Über zwei Arten von Faktorenfolgen in der Theorie der algebraischen Gleichungen, J. Reine Angew. Math., 144 (1914), 89-113; cf. pp. 96-767.

10. H. Skovgaard, On inequalities of the Turán type, Mathematicae Scandinavica, 2 (1954), 65-73.

11. O. Szász, Inequalities concerning ultraspherical polynomials and Bessel functions, Proc. Amer. Math. Soc., 1 (1950), 256-257.

12. Identities and inequalities concerning orthogonal polynomials and Bessel functions, J. Analyse Math., 1 (1951), 116-134.

13. G. Szegö, On an inequality of P. Turán concerning Legendre polynomials, Bull. Amer. Math. Soc., 54 (1948), 401-405.

14. V. R. Thiruvenkatachar and T. S. Nanjundiah, Inequalities concerning Bessel functions and orthogonal polynomials, Proc. Indian Acad. Sci., Sect. A., 33 (1951), 373-384. 15. K. Venkatachaliengar and S. K. Lakshmana Rao, On Turán's inequality for ultraspherical polynomials, Proc. Amer. Math. Soc., 8 (1957), 1075-87.

16. M. S. Webster, Non-linear recurrence relations for certain classical functions, Amer. Math. Monthly, 64 (1947), 249-252.

Received October 4, 1971. This paper was written while the author was a visitor at the Seminar für angewandte Mathematik, ETH, Zürich.

\section{DUKE UNIVERSITY}




\section{PACIFIC JOURNAL OF MATHEMATICS}

\section{EDITORS}

\section{H. SAMELSON}

Stanford University

Stanford, California 94305

C. R. Новву

University of Washington Seattle, Washington 98105

\section{J. DuGundJI}

Department of Mathematics University of Southern California Los Angeles, California 90007

RICHARD ARENS

University of California Los Angeles, California 90024

\section{ASSOCIATE EDITORS}
E. F. BECKENBACH
B. H. NeumanN
F. WOLF
K. YoSHIDA

\section{SUPPORTING INSTITUTIONS}

\author{
UNIVERSITY OF BRITISH COLUMBIA \\ CALIFORNIA INSTITUTE OF TECHNOLOGY \\ UNIVERSITY OF CALIFORNIA \\ MONTANA STATE UNIVERSITY \\ UNIVERSITY OF NEVADA \\ NEW MEXICO STATE UNIVERSITY \\ OREGON STATE UNIVERSITY \\ UNIVERSITY OF OREGON \\ OSAKA UNIVERSITY
}

\author{
UNIVERSITY OF SOUTHERN CALIFORNIA \\ STANFORD UNIVERSITY \\ UNIVERSITY OF TOKYO \\ UNIVERSITY OF UTAH \\ WASHINGTON STATE UNIVERSITY \\ UNIVERSITY OF WASHINGTON \\ $*{ }^{*}$
AMERICAN MATHEMATICAL SOCIETY
NAVAL WEAPONS CENTER
}

The Supporting Institutions listed above contribute to the cost of publication of this Journal, but they are not owners or publishers and have no responsibility for its content or policies.

Mathematical papers intended for publication in the Pacific Journal of Mathematics should be in typed form or offset-reproduced, (not dittoed), double spaced with large margins. Underline Greek letters in red, German in green, and script in blue. The first paragraph or two must be capable of being used separately as a synopsis of the entire paper. The editorial "we" must not be used in the synopsis, and items of the bibliography should not be cited there unless absolutely necessary, in which case they must be identified by author and Journal, rather than by item number. Manuscripts, in duplicate if possible, may be sent to any one of the four editors. Please classify according to the scheme of Math. Rev. Index to Vol, 39. All other communications to the editors should be addressed to the managing editor, Richard Arens, University of California, Los Angeles, California, 90024.

50 reprints are provided free for each article; additional copies may be obtained at cost in multiples of 50 .

The Pacific Journal of Mathematics is issued monthly as of January 1966. Regular subscription rate: $\$ 48.00$ a year (6 Vols., 12 issues). Special rate: $\$ 24.00$ a year to individual members of supporting institutions.

Subscriptions, orders for back numbers, and changes of address should be sent to Pacific Journal of Mathematics, 103 Highland Boulevard, Berkeley, California, 94708.

PUBLISHED BY PACIFIC JOURNAL OF MATHEMATICS, A NON-PROFIT CORPORATION

Printed at Kokusai Bunken Insatsusha (International Academic Printing Co., Ltd.), 270, 3-chome Totsuka-cho, Shinjuku-ku, Tokyo 160, Japan. 


\section{Pacific Journal of Mathematics}

\section{Vol. 44, No. $2 \quad$ June, 1973}

Tsuyoshi Andô, Closed range theorems for convex sets and linear liftings . . . . . . 393

Richard David Bourgin, Conically bounded sets in Banach spaces . . . . . . . . . 411

Robert Jay Buck, Hausdorff dimensions for compact sets in $R^{n} \ldots \ldots \ldots \ldots \ldots \ldots . \ldots 421$

Henry Cheng, A constructive Riemann mapping theorem ................ 435

David Fleming Dawson, Summability of subsequences and stretchings of

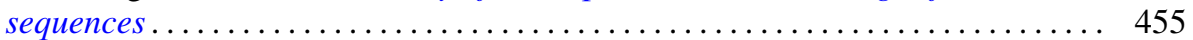

William Thomas Eaton, A two sided approximation theorem for 2-spheres ....... 461

Jay Paul Fillmore and John Herman Scheuneman, Fundamental groups of compact complete locally affine complex surfaces ....................... 487

Avner Friedman, Bounded entire solutions of elliptic equations . . . . . . . . . . . 497

Ronald Francis Gariepy, Multiplicity and the area of an $(n-1)$ continuous

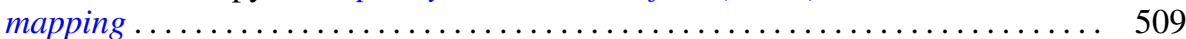

Andrew M. W. Glass, Archimedean extensions of directed interpolation groups . . . . 515

Morisuke Hasumi, Extreme points and unicity of extremum problems in $H^{1}$ on

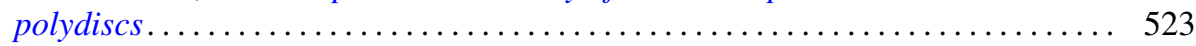

Trevor Ongley Hawkes, On the Fitting length of a soluble linear group . . . . . . 537

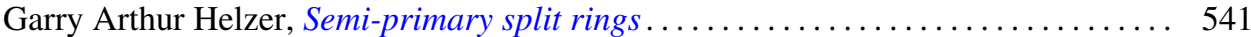

Melvin Hochster, Expanded radical ideals and semiregular ideals . . . . . . . . . 553

Keizō Kikuchi, Starlike and convex mappings in several complex variables . . . . . . 569

Charles Philip Lanski, On the relationship of a ring and the subring generated by its

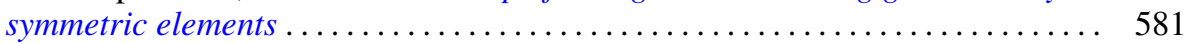

Jimmie Don Lawson, Intrinsic topologies in topological lattices and semilattices ........................................... 593

Roy Bruce Levow, Counterexamples to conjectures of Ryser and de Oliveira ...... 603

Arthur Larry Lieberman, Some representations of the automorphism group of an infinite continuous homogeneous measure algebra ..........

William George McArthur, $G_{\delta}$-diagonals and metrization theorems $\ldots .$.

James Murdoch McPherson, Wild arcs in three-space. II. An invariant of

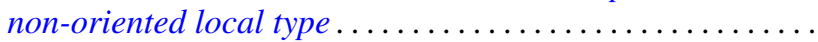

H. Millington and Maurice Sion, Inverse systems of group-valued measures ...

C. Edward Moore, Concrete semispaces and lexicographic separation of convex

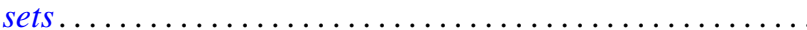

Jingyal Pak, Actions of torus $T^{n}$ on $(n+1)$-manifolds $M^{n+1}$.

Merrell Lee Patrick, Extensions of inequalities of the Laguerre and Turán type . . . . 675

Harold L. Peterson, Jr., Discontinuous characters and subgroups of finite index. . . . 683

S. P. Philipp, Abel summability of conjugate integrals . . . . . . . . . . . . . 693

R. B. Quintana and Charles R. B. Wright, On groups of exponent four satisfying an

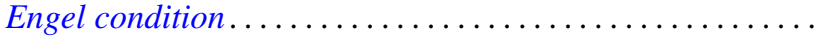

Marlon C. Rayburn, On Hausdorff compactifications. . . . . . . . . .

Martin G. Ribe, Necessary convexity conditions for the Hahn-Banach theorem in

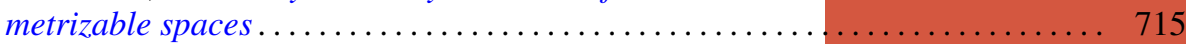

Ryōtarō Satō, On decomposition of transformations in infinite measure spaces .... 733

Peter Drummond Taylor, Subgradients of a convex function obtained from a

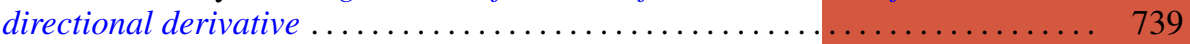

James William Thomas, A bifurcation theorem for $k$-set contractions . . . . . . . . 749 Clifford Edward Weil, A topological lemma and applications to real functions . . . . 757

Stephen Andrew Williams, A nonlinear elliptic boundary value problem . . ....... 767

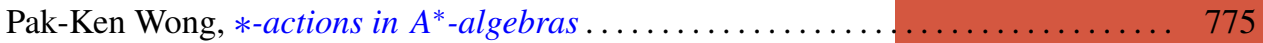

